\title{
ANALISIS LATAR DAN KARAKTER TOKOH UTAMA DALAM NOVEL THE WOMAN IN THE WINDOW KARYA A. J. FINN
}

\author{
Nisar Yulianti ${ }^{1}$, \\ Syahfitri Purnama ${ }^{2}$, \\ Fakultas Pascasarjana, Universitas Indraprasta PGRI \\ e-mail: nisar.yulianti@gmail.com ${ }^{1}$ \\ e-mail: syahfitripurnama@gmail.com ${ }^{2}$
}

\begin{abstract}
Abstrak: Tujuan Penelitian ini adalah untuk menganalisis aspek latar dan karakter tokoh utama Anna Fox dalam novel The Woman In The Window karya A.J.Finn. Sumber data penelitian ini adalah primer dan sekunder. Sumber data primer pada penelitian ini adalah buku-buku acuan yang berhubungan dengan permasalahan yang menjadi objek penelitian. Metode penelitian yang digunakan oleh peneliti yaitu, metode kualitatif deskriptif. Hasil penelitian yang peneliti lakukan adalah, 1. Latar yang terdapat dalam novel The Woman In The Window karya A.J. Finn ini berjumlah dua puluh lima (25) data. a) latar tempat berjumlah 19, b) latar waktu berjumlah 14, dan c) latar sosial berjumlah 12. Sedangkan karakter tokoh utama Anna Fox yang dipengaruhi oleh id adalah empati, keras kepala, bijaksana dan nekat. Sedangkan, karakter yang termasuk ego adalah percaya diri, nekat, perhatian dan teguh pendirian. Sedangkan perwatakan yang termasuk superego meliputi bijaksana, pasrah, perhatian dan jujur.
\end{abstract}

Kata kunci: Aspek Latar, Aspek Karakter Tokoh Utama, Novel dan Karya A.J.Finn.

\section{Pendahuluan}

Novel merupakan salah satu bentuk karya sastra yang sekaligus disebut fiksi (Nurgiyantoro, 2014, hal. 11). Unsur intrinsik dan ekstrinsik dalam novel memberi suatu kerangka atau struktur dalam sebuah novel. Latar merupakan salah satu unsur intrinsik pembangun sebuah novel. Menurut Abrams (dalam Nurgiyantoro, 2014, hal. 302) pengertian latar (atau biasa dikenal sebagai setting) menunjukkan pada tempat, yaitu lokasi di mana cerita itu terjadi, waktu, kapan cerita itu terjadi dan lingkungan sosial-budaya, keadaan kehidupan bermasyarakat tempat tokoh dan peristiwa terjadi. Sebagaimana dikemukakan di atas, latar terdiri dari tiga unsur, yaitu tempat, waktu dan lingkungan sosial-budaya. Kondisi latar dari sebuah novel mampu membuat pembacanya seolah ikut bermain dan menikmati segala realitas hidup yang dialami oleh tokoh. Penulis novel mampu mendeskripsikan kondisi latar dengan sempurna sebagai tumpuan cerita secara konkret dan jelas.

Kehadiran seorang tokoh dalam karya sastra atau suatu cerita merupakan hal yang sangat penting karena tokoh berperan sebagai penggerak cerita sehingga penafsiran tentang kehidupan itu tampak walaupun hanya rekaan. Aspek tokoh dalam karya sastra fiksi merupakan salah satu elemen dalam faktafakta cerita yang sangat penting kehadirannya. Terlebih tokoh utama yang menjadi poros sebuah karya sastra dalam sebuah novel.

Salah satu novel yang menarik latar dan karakter tokoh utamanya adalah novel The Woman in The Window (Finn, 2018). Sebagian besar latar yang diangkat dalam cerita adalah ruangan di apartemen yang terdapat jendela menghadap ke selatan sebagai tempat favorit Anna Fox untuk melihat seluruh aktivitas tetangganya. Dalam ruangan itu ia menghabiskan hari demi hari dalam setahun lamanya untuk melakukan aktivitas kegemarannya itu. Hal itu disebabkan karena ia mengidap agorafobia karena kecelakaan masa lalu di hutan yang menewaskan suami dan anaknya. Riwayat gangguan panik ini berasal dari konsep yang dikemukakan oleh Jacob Mendes DaCosta pada tahun 1833 meliputi gejala psikologis dan somatik (Kaplan et al., 2007).

Serangan panik yang dialami oleh Anna Fox sebagai tokoh utama dalam novel ini terasa sangat nyata dan mampu menghanyutkan para pembacanya, dengan bahasa sastra yang sarat dengan kandungan 


\section{INFERENCE: Journal of English Language Teaching}

Vol. 4, No. 1, April - July 2021

p-ISSN: 2615-8671

e-ISSN: 2615-868X

psikologi itu menjadi daya tarik tersendiri dalam menyelami rangkaian plot keseluruhan. Mulai dari gejala cemas berlebihan diikuti oleh jantung berdebar-debar, nyeri pada dada, sesak nafas, tremor, pusing, merasa dingin atau panas (Yaunin, 2012). Pengalaman ini begitu indah dirasakan sebagai penyelaman dan penghayatan pada cerita. Gangguan panik yang ia alami ini merupakan serangan panik yang berulang-ulang dengan cepat dan durasi sangat singkat. Anna Fox merasakan ketakutan yang kuat dan sering berpikir ia akan kehilangan kontrol atau menjadi gila. Dengan gangguan psikologis demikian membuat ia menghindari tempat-tempat atau situasi serangan paniknya pernah terjadi terutama tempat keramaian atau tempat yang susah untuk menyelamatkan diri. Tetapi sebagian peneliti lain kurang setuju karena Agorafobia bisa juga tanpa riwayat Gangguan panik. Serangan panik bisa juga ditemukan pada gangguan mental lain (seperti: gangguan depresi) dan kondisi medik tertentu (seperti: gangguan putus zat atau keracunan) (Taylor et al., 2008, hal. 429).

Berdasarkan latar dan karakter yang sangat kompleks dalam sebuah karya fiksi sangat menarik untuk diteliti. Pengkajian dalam karya sastra dapat dibantu dengan berbagai disiplin limu, salah satunya ilmu psikologi sastra. Teori psikologi yang digunakan dalam penelitian ini teori Psikoanalisis Sigmund Freud. Menurut Freud pada umumnya dibagi menjadi tiga yaitu Id, ego, dan superego. Id adalah dorongandorongan primitif yang harus dipuaskan, salah satunya yaitu hasrat. Id dengan demikian merupakan kenyataan subyektif prima, dunia batin sebelum individu mengalami pengalaman tentang dunia luar. Ego bertugas untuk mengontrol Id, sedangkan super ego berisi suara hati (Hall \& Lindzey, 2003, hal. 63-68). Latar dan karakter tokoh utama dalam novel ini mampu menjadi inspirasi bagi siapa saja yang mengalami gangguan kejiwaan atau psikologis khususnya agorafobia untuk mampu bangkit dari kegelisahan dan kepanikan yang berlebih menjadi manusia yang memiliki kehidupan yang lebih baik dan bahagia dengan meraih ketenteraman yang sempurna.

\section{Metode}

Dalam penelitian ini menggunakan metode kualitatif deskriptif. Paparan data yang disajikan dalam penelitian ini ditegaskan dalam bentuk lampiran tabel pemaparan data yang diperoleh dari pemahaman makna yang terdapat pada setiap kata, kalimat, paragraf, teks dan juga unsur pengembangan karya sastra. Pemahaman makna secara keseluruhan, dilakukan penafsiran dan pengategorian data yang terkandung dalam novel The Woman In The Window, yang selanjutnya data-data tersebut dianalisis berdasarkan pengategoriannya. "Metode kualitatif mempunyai sebelas ciri, yaitu: (1) latar pelaksanaan penelitian kualitatif adalah alamiah, sesuai dengan konteks yang alami; (2) instrumen penelitian kualitatif adalah manusia atau peneliti; (3) ada tiga metode yang diterapkan oleh peneliti kualitatif, yaitu: (a) pengamatan: (b) wawancara; (c) telaah dokumen; (4) metode menganalisis data dalam penelitian ada dua, yaitu deduktif (diterapkan dalam penelitian kualitatif) dan induktif (diterapkan pada penelitian alamiah); (5) menurut penelitian kualitatif, teori lahir dari data, bukan teori melahirkan data; (6) deskriptif adalah sifat data penelitian kualitatif. Wujud datanya berupa deskriptif objek penelitian; (7) proses lebih dipentingkan dalam penelitian kualitatif; (8) batas ditentukan oleh fokus dalam penelitian kualitatif; (9) validitas, reliabilitas, dan objekfitas penelitian kualitatif berbeda dengan kuantitatif; (10) desain penelitian kualitatif bersifat sementara; (11) hasil penelitian berupa pengertian dan interpretasi yang dihasilkan melalui kesepakatan sumber data dan informan (Ratna, 2006).

Metode deskriptif kualitatif, yaitu suatu prosedur yang menggunakan data deskriptif berupa katakata tertulis atau lisan dari objek yang diamati. Dalam hal ini objek yang diamati adalah novel The Woman In The Window karya A. J. Finn dalam kaitan dengan latar dan tokoh utamanya. Metode ini dimaksud untuk memberikan gambaran, analisis dan penjabaran secara objektif agar dapat mengungkapkan hubungan antar unsur-unsur cerita di dalam teks dan dapat menggambarkan cerita dan konflik psikologi yang terkandung di dalamnya. Metode ini digunakan untuk menggambarkan hal-hal faktual yang terdapat dalam karya sastra sehingga pembaca mendapatkan gambaran yang jelas mengenai hal-hal yang menyebabkan Agorafobia dan mengatasinya yang terkandung dalam latar pada novel The Woman In The Window karya A. J. Finn. Pendekatan yang digunakan untuk menganalisis novel ini adalah pendekatan objektif lalu juga ditinjau berdasarkan psikologi sastra yang penelitiannya dipusatkan kepada keterkaitan dengan yang terjadi di dalam karya sastra (Minderop, 2010; Ratna, 2013). Lalu jenis penelitian yang akan peneliti pergunakan adalah penelitian kepustakaan. Dalam penulisan ini, peneliti menggunakan pendekatan psikologi sastra dengan menghubungkan cerita dalam novel The Woman in The Window karya A. J. Finn dengan keadaan 
jiwa tokoh utama, yakni latar belakang yang menyebabkan Agorafobia dan karakter tokoh utama yaitu Anna Fox

\section{Hasil dan Diskusi}

Berdasarkan penelitian yang telah dilakukan, maka latar yang terdapat dalam novel The Woman in The Window karya A.J. Finn ini berjumlah dua puluh lima (25) data yang terdapat pula dalam lampiran. 1) latar tempat berjumlah 19,2) latar waktu berjumlah 14, dan 3) latar sosial berjumlah 12. Penjelasannya dapat dilihat pada temuan data berikut ini.

\section{Latar Tempat}

Latar tempat yang mendominasi novel The Woman In The Window ini adalah Rumah Anna Fox. Seperti: jendela, tangga, ruang duduk, lantai bawah, dapur, kamar, lantai atas, ruang komputer, ruang kerja lorong dan perpustakaan. Selain itu ada kisah-kisah masa lalu Anna Fox yang memunculkan latar tempat, seperti di pesawat, di Baltimore, di laut lepas dan jembatan di pantai timur.

\section{Latar Waktu}

Latar waktu berhubungan dengan masalah kapan terjadinya peristiwa-peristiwa yang diceritakan dalam sebuah karya fiksi. Masalah "kapan" tersebut biasanya dihubungkan dengan peristiwa sejarah. Pengetahuan dan persepsi pembaca terhadap waktu sejarah itu kemudian dipergunakan untuk mencoba masuk ke dalam suasana cerita, apakah berupa penanggalan, penyebutan peristiwa bersejarah, penggambaran situasi malam, siang, sore, dan lain-lain. Misalnya, Senin, sekarang, 16 Desember, pada zaman dahulu, atau pada pukul 13.00 WIB. Semua itu merupakan berbagai keterangan tentang latar waktu. Latar waktu dalam novel The Woman In The Window, Pertama, latar waktu yaitu dengan kata-kata "Setahun". Waktu dijelaskan tokoh Anna Fox dalam novel merupakan 365 kalau dihitung dengan hari. Kedua, waktu yang dijelaskan tokoh dalam novel merupakan waktu, pagi, siang hingga malam hari. Waktu itu dijelaskan secara rinci dan diurai di dalam novel ini. Ketiga, menjelang malam, tiga hari kemudian, malam itu, empat bulan dan pertengahan Februari, pada Agustus silam, pukul lima.

\section{Latar Sosial}

Latar sosial menyaran pada hal-hal yang berhubungan dengan perilaku kehidupan sosial masyarakat di suatu tempat yang diceritakan dalam karya fiksi. Tata cara kehidupan sosial masyarakat mencakup berbagai masalah dalam lingkup yang cukup kompleks. Ia dapat berupa kebiasaan hidup, adat istiadat, tradisi, keyakinan, pandangan hidup, cara berpikir dan bersikap, dan lain-lain. Latar sosial juga berhubungan dengan status sosial tokoh yang bersangkutan, misalnya rendah, menengah, dan atas. Latar sosial dalam novel The Woman In The Window yakni, kebiasaan Anna Fox menonton film hitam putih untuk menemani hari-harinya, kebiasaannya menikmati minuman keras untuk menghilangkan kekhawatirannya, mengonsumsi obat-obatan yang diresepkan oleh dokternya, dan situasi menghadapi pasien-pasiennya. Latar sosial terlihat jelas dari peristiwa yang dialami oleh tokoh Anna Fox dengan cara berpikir, sikap dan keyakinan, cara tokoh meyakini sesuatu, nilai dan norma sosial, cara tradisi/kebiasaan hidup.

\section{Deskripsi Temuan Karakter Tokoh Utama Anna Fox}

Karakter adalah penggambaran kualitas tokoh baik yang berupa sifat lahir dan batin manusia yang mempengaruhi setiap pikiran dan tingkah lakunya, sehingga membedakan dengan tokoh yang lainnya. Watak tokoh digambarkan oleh pengarang melalui ucapan, tingkah laku tokoh yang dilihat dari narasi, dialog ataupun monolog para tokohnya. Karakter tokoh utama dalam novel The Woman In The Window karya A.J.Finn adalah meliputi empati, percaya diri, perhatian, teguh pendirian, pasrah, jujur, bijaksana, namun dalam beberapa kondisi Anna Fox juga memiliki watak yang kurang baik yaitu keras kepala dan nekat. Berikut hasil penelitian karakter tokoh utama Anna Fox dalam novel The Woman In The Window karya A.J.Finn yang terdapat pula dalam lampiran.

Tabel 1. Karakter Tokoh Utama Anna Fox

\begin{tabular}{|l|l|l|l|}
\hline No. & $\begin{array}{l}\text { Struktur } \\
\text { Kepribadian }\end{array}$ & Wujud & No. Data \\
\hline \multirow{2}{*}{1 a. } & \multirow{2}{*}{ Id } & Empati & 1 \\
\cline { 3 - 4 } & & Keras kepala & $2,21,23$ \\
\cline { 3 - 4 } & & Bijaksana & 13 \\
\hline
\end{tabular}


INFERENCE: Journal of English Language Teaching

Vol. 4, No. 1, April - July 2021

p-ISSN: 2615-8671

e-ISSN: 2615-868X

\begin{tabular}{|l|l|l|l|}
\hline & & Nekat & $8,10,12,21,22,24$ \\
\hline \multirow{3}{*}{$2 \mathrm{~b}}$. & \multirow{3}{*}{ Ego } & Percaya diri & $4,6,18,20$ \\
\hline \multirow{3}{*}{$3 \mathrm{c.}$} & Nekat & $16,17,19,25$ \\
\hline & Perhatian & 5 \\
\hline & Seguh pendirian & 14 \\
\hline \multirow{3}{*}{ Super Ego } & Bijaksana & $3,7,73$ \\
\hline & & Pasrah & 7,11 \\
\hline & Perhatian & 9 \\
\hline & Jujur & 15 \\
\hline
\end{tabular}

\section{Simpulan}

Berdasarkan hasil penelitian dan pembahasan terhadap novel The Woman In The Windwo karya A.J. Finn, maka dapat ditarik simpulan latar dan karakter tokoh utama Anna Fox sebagai berikut.

1. Latar

a) Latar tempat yang terdapat dalam novel The Woman In The Window karya A.J. Finn yaitu di rumah, di puncak tangga, jendela atap, di ruang duduk, di samping perapian, ke lantai bawah, ke dapur, di meja, di Midtown, di Lenox Hill, dari satu ujung ke ujung lain kasur, ke lantai atas, di belakang mejaku, di depan komputer, Agora, di situs penggemar film klasik, di atas mejaku, di atas sana, di dalam pesawat atau di atas awan, pulau di bawah sana, lorong satu-satunya area rumah, antara rumahku dan dunia luar, di dalam rumah, di Baltimore, di pojok ruang kerjaku, menuruni tangga menuju televisi, Kakiku melewatkan anak tangga pertama seluruhnya, menginjak keras anak tangga kedua, ke atas rumput, di perpustakaan Ed, dan di ranjang.

b) Latar waktu yang terdapat dalam novel The Woman In The Window karya A.J. Finn yaitu pukul sebelas pada Senin dan Jumat, antara pukul lima dan lima tiga puluh, pada sore hari, pada pagi hari, setahun, September, berbulan-bulan, hampir setahun, menjelang malam, sepuluh bulan yang lalu, Pertengahan Februari lalu- setelah hampir enam minggu, lima tahun yang lalu, Pukul lima, malam ini, pada Agustus silam, dalam kegelapan, cahaya matahari tengah hari menggenang di karpet, pukul sebelas lewat, dan sebelum tengah hari.

c) Latar sosial dalam novel The Woman In The Window karya A.J.Finn yaitu didominasi kebiasaan hidup dan cara berpikir dan bersikap tokoh utama dalam novel tersebut yakni Anna Fox. Tata cara kehidupan sosial masyarakat mencakup berbagai masalah dalam lingkup yang cukup kompleks. Ia dapat berupa kebiasaan hidup, adat istiadat, tradisi, keyakinan, pandangan hidup, cara berpikir dan bersikap, dan lain-lain. Latar sosial juga berhubungan dengan status sosial tokoh yang bersangkutan, misalnya rendah, menengah, dan atas. Perlu ditegaskan bahwa latar sosial merupakan bagian latar secara keseluruhan. Jadi, latar sosial berada dalam kepaduan dengan unsur latar yang lain, yaitu unsur tempat dan waktu.

Hasil penelitian terhadap novel The Woman In The Window karya A.J.Finn, menunjukkan bahwa karakter tokoh utama yang dipengaruhi oleh id adalah empati, keras kepala, bijaksana dan nekat. Sedangkan, karakter yang termasuk ego adalah percaya diri, nekat, perhatian dan teguh pendirian. Sedangkan perwatakan yang termasuk super ego meliputi bijaksana, pasrah, perhatian dan jujur.

\section{Daftar Rujukan}

Finn, A. J. (2018). The woman in the window (1st ed.). HarperCollins. https://books.google.no/books?id=hxCkDgAAQBAJ\&printsec=frontcover\&dq=the+woman+in+the +window\&hl=en\&sa=X\&ved=2ahUKEwjOjsO1_JDvAhUNs6QKHc3ADnMQ6AEwAHoECAEQ $\mathrm{Ag} \# \mathrm{v}=$ onepage $\& \mathrm{q} \& \mathrm{f}=$ false

Hall, C., \& Lindzey, G. (2003). Teori-teori psikodinamik (Klinis) (A. Supratiknya (penerj.)). Kanisius.

Kaplan, H., Sadock, \& J, B. (2007). Synopsis of psychiatry: Behavioral sciences, clinical psychiatry. International Clinical Psychopharmacology, 4. https://doi.org/10.1097/00004850-198904000-00007

Minderop, A. (2010). Psikologi Sastra: Karya Sastra, Metode, Teori, dan Contoh Kasus (1st ed.). Yayasan 
Pustaka Obor Indonesia.

Nurgiyantoro, B. (2014). Teori Pengkajian Fiksi. Universitas Gadjah Mada Press.

Ratna, N. K. (2006). Teori, Metode, dan Teknik Penelitian Sastra dari Strukturalisme hingga Postrukturalisme Perspektif Wacana Naratif. Pustaka Pelajar.

Ratna, N. K. (2013). Paradigma sosiologi sastra. Pustaka Pelajar. https://pustaka.kemdikbud.go.id/libdikbud/index.php?p=show_detail\&id=21749

Taylor, C. T., Pollack, M. H., LeBeau, R. T., \& Simon, N. M. (2008). Anxiety Disorders: Panic, Social Anxiety, and Generalized Anxiety. In Massachusetts General Hospital Comprehensive Clinical Psychiatry (hal. 429-446). Elsevier. https://doi.org/10.1016/B978-0-323-04743-2.50034-2

Yaunin, Y. (2012). Gangguan panik dengan agrofobia. Majalah Kedokteran Andalas, 36(2), 234-243. https://doi.org/10.22338/mka.v36.i2.p234-243.2012 